\title{
Family Care, Social Services, and Living Arrangements Factors Influencing Psychosocial Well-Being of Elderly from Selected Households in Ibadan, Nigeria
}

\author{
D. Oladeji \\ Department Family, Nutrition and Consumer Sciences, Obafemi Awolowo University, Ile-Ife, Nigeria \\ Correspondence should be addressed to D. Oladeji, dijideji@yahoo.co.uk
}

Received 7 June 2011; Revised 5 September 2011; Accepted 20 September 2011

Academic Editor: Wayne Martino

Copyright (C) 2011 D. Oladeji. This is an open access article distributed under the Creative Commons Attribution License, which permits unrestricted use, distribution, and reproduction in any medium, provided the original work is properly cited.

\begin{abstract}
This study examined family care, social services, and living arrangements factors influencing the psychosocial well-being of the elderly from selected households in Ibadan, Nigeria. The participants for the study consisted of 280 elderly persons randomly drawn from selected households in five local government areas of Ibadan metropolis. A descriptive survey design was employed in collecting the data from the respondents. Data collected were analyzed using chi-square $\left(\chi^{2}\right)$ statistics. Results obtained indicated that significant relationships existed between family care $\left(\chi^{2}=127.9, \mathrm{df}=12, P<.05\right)$, social services $\left(\chi^{2}=191.9\right.$, $\mathrm{df}=12$, $P<.05)$, and living arrangements $\left(\chi^{2}=14.4, \mathrm{df}=6, P<.05\right)$ and psychosocial well-being of elderly. The results implicate the need for the framework on the complex system of the elderly services. These areas of service include economic services, attitudes toward aging, roles played by the elderly, and health care services.
\end{abstract}

\section{Introduction}

Aging is not an entirely negative process, but old age is undoubtedly a difficult period, worsened by the inadequacy of social institutions to care for the aged [1]. Some studies have found no differences among the young and the elderly on measures of satisfaction, morale, and general happiness, and some studies show that elderly have a more positive selfconcept than the younger ones.

Old age is often said to begin at 65 , which in our society (Nigerian reference) is a typical age of retirement. In some part of the world, where life expectancy is lower, a person might be old at 35 or 40 . Even in our own society (i.e., Nigeria), we see enormous variation among older people. Neugarten [2], therefore, gave the reason for this variation that "old age" is quite a long period of time, encompassing many phases and changes. Hence, he has divided older individuals into three distinct groups as follows:

(i) the young-old, those between 55 and 65 , who are still working and at peak of their social and vocational status in life, (ii) the middle-old, those between 65 and 75 , the majority of whom are retired and in good health and who have abundant time to follow their interest, and

(iii) the old-old, those over age 75 , who as a group are the frailest and poorest of the old.

Family care has been one of the focal points in this study. Families have been the major resource, and until very recently their responsibility for relatives was enforced morally, culturally, and through law. For instance, relative responsibility laws held adult children responsible for the support of their parents. Today, if children could not take an older parent needing care into their homes, then they were responsible for paying at least some of the costs for caring for that parent in an institution or elsewhere [3]. And although moral and cultural influences continue to pressure children to care for their parents, social change has made it increasingly difficult.

However, elder care in the United States is provided primarily in two ways: institutions for the elderly and private care at home. The latter is peculiar to Nigeria situation, whereby most care of older people is provided informally 
by families. Family members provide 80 to 90 percent of long-term care for the elderly. But in the United States both institutional care of elderly and private care at home were considered significant $[4,5]$. Relatively, old people in Nigeria generally live in and receive care at their homes or the residence of children or relations [6]. Many older people, for instance, would prefer to remain in their own homes or homes of relatives simply because, home health care, meal and homemaker are available which may possibly prevent more costly institutional care.

In Shanas [7] and Mancini and Blieszner [8], findings from their studies showed that there are always contact relationships between older people and their families or relatives. They found out that 7 out of every 10 older people with children and said that they helped children, and 7 out of every 10 older people helped their grandchildren. Seven out of 10 older people also said that they received help from their children. This help included home repairs and housework, care in an illness, and different kinds of gifts. In addition, older people helped their adult children by caring for grandchildren. In short, it appears that older people are not isolated from younger family members and that these contacts are generally happy ones.

In Nigeria, many families do discharge their duties to the elderly creditably by providing special needs to the elderly [6]. For instance, most older married couples express general satisfaction with their marriage and the mutual emotional support that it brings. The majority have adult children with whom they maintain contact. Few older adults live with their children, and most do not want to, preferring instead to remain as independent as possible.

Having discussed family care to the elderly, the needs of older people include not only this, but also intangible services. In recent years, with the emphasis on maintaining older people in the community, it has been found that a variety of supportive services are needed. These include information and referral services, homemaker and home health services, home-delivered meals, socialization services, transportation services, and legal assistance. Some of these have long been provided by the private social agencies.

In recent years, a wide array of social, health, and related support services have either been developed or extended to provide the needs of the aged. In Nigeria, there are some enactments designed to protect the interest of the elderly. For example, the 1989 National Social Development Policy stipulated the main objectives in respect of the elderly and allocates responsibilities [6]. Ironically, no governmental agencies are seen to execute that policy effectively.

However, the 1989 policy stipulated and provided under section 5, 16 (1), and 17 (3) f and g that:

"The state shall direct its policy towards ensuring that ... Old age care and pensions ... and sick benefits are provided for all citizens children, young persons and the aged are protected against any exploitation whatsoever and against moral and material neglect, and provision is made for public assistance in deserving cases or other conditions of need."
In addition, a number of State governments announced free medical services for all citizens aged 65 and above. Unfortunately, the implementation of the constitutional care of aged or the enforcement of the legal duty to provide necessaries of life for the aged appear to be no man's business; the provisions just remain elegant and pious, with little or no implementation.

Okunola [6] observed that old people in Nigeria generally live in and receive care in their own houses or the residence of children or relations. This, however, is not saying that the care is satisfying or that there are no cases of neglect of the aged. Other social services which are essential to a happy and comfortable old age include income security, health care, transportation, housing, and employment.

In the United States, there has been the "Older Americans Act of 1965 " which provides supplementary services through funding of nutrition programmes, transportation, social services, and the coordination of services for the aged. Through the auspices of this "Older Americans Act," "Area wide Agencies on Aging (AAAs)" have been established throughout the country that coordinate services to the ages. Among their many functions are such activities as assessing the needs of the older population, providing or coordinating for congregate meals programmes, developing transportations services, serving as information and referral resources, and acting as advocates for the aged in assuring that communities will be attentive to their needs [9].

Similarly, in Nigeria, adequate income security is essential to a happy and comfortable old age. Pension for old age people should be regarded as payment for previous services. It is a right as stipulated in 1979 and 1999 constitutions of the Federal Republic of Nigeria. Having realized the meager allowances and gratuity of the elderly retired civil servants, there has been a reasonable review of these by the Abubakar and Obasanjo's administrations in 1998 and 1999, respectively. Thus, as Obasanjo took the mantle of power in May, 1999 from the military, he made life easy for the pensioners, especially the elderly retired civil servants by improving their socioeconomic status $[6,10]$.

Although the majority of older adults are home owners, housing often is a major concern of them. The rate of substandard homes among the elderly exceeds those for other age groups. Many houses become dilapidated over the years, and in later life the ability of older adults to maintain or repair them is often limited by low incomes. In addition, older adults find it very difficult to secure home repair loans. Likewise, in Nigeria, government housing for the aged typically is difficult to secure because of the high demand for lowcost housing units. Even when available, low-cost housing appears unattractive, impersonal, lacking in privacy, and too noisy. More units are needed for older adults but not likely to be forthcoming due to government budgetary limits [9].

Furthermore, Heffeman et al. [9] see transportation as being essential for grocery shopping, attending church services, keeping appointments with doctors and dentists, visiting friends, and maintaining contact with the family. The absence of transportation has resulted in many old people becoming home bound. Often the result is social isolation, which leads to the loss of incentive, decreased activity, 
self-depreciation, and eventually psychological and physical deterioration, thus, confirming the stereotype that older adults elect not to participate in the mainstream of life. Unfortunately, little has been accomplished in addressing transportation needs of the aged. Indeed, government budget cuts have significantly reduced transportation programmes designed for the elderly in many communities (including Nigeria where there is no even provision for it).

Living arrangement of the elderly is the living with others and their relationships with others at old age. The great majority of people live with others throughout their lives. This has been a fact across the course of history and is pretty much universal. The unfortunate correlate, however, is the implication that people who live alone are somehow odd or different. Because it is expected, living with others has assumed the status of a norm; thus, those who live alone for some reason are seen as somehow not being normal. Single people at all ages might testify to this rather irritating fact of life [11].

Skidmore et al. [12] in their findings showed that the goal for housing the elderly has been greatly broadened from the old concept of providing a quiet place in the country to providing a variety of choices from which older persons can select one suited to their needs. For most, the preferable way to live is to remain in their own homes or to live with their children or relatives. However, the reason why an increased trend toward living alone may not be such a drawback for older people is that friends are such an important source of satisfaction and social support for them. Most elderly people spend a substantial amount of time cultivating friendships with peers. In one study, half of the older people questioned reported having between eleven and forty friends on whom they could call for assistance in their daily lives [13].

With their increased connections to others, their own age, most elderly people do not see themselves as lonely, not even those who are widowed, divorced, or never married. In one study of Russell [14], 88 percent of those over sixtyfive reported that loneliness was not a problem for them. Interestingly, loneliness may be a less matter of one's degree of separation from other people and a more matter of one's expectations for community. Rather, according to Jylhä and Jokela [15], it is in societies where expectations for community run high, yet the structures facilitating it are eroding, that feelings of loneliness are most common.

In terms of living arrangements of elderly persons in later life, the clear trend has been toward increasing home ownership over the years. It is believed that about $80 \%$ of the elderly own their own homes (US Bureau of the Census, 1997). Associated with the living arrangements is the increasing freedom older persons now have compared to earlier generations. The number of older people living alone has increased during recent decades because older people are financially off enough to live by themselves. Fewer are dependent on family members for housing or support. Widows increasingly have assets and pensions of their own; fewer are forced to depend only on what their husbands left for them. All these have contributed greatly to the ability of older persons to afford independent living [11].
Also associated with this freedom, the current generation of older persons are unlike their parents and grandparents in that there is less reliance on kin for assistance because more older people live in their own household, resulting in fewer day-to-day contacts with family members they might rely upon for assistance although researchers have shown that family members remain the greatest source of help for elder persons $[11,16]$. Another factor that has changed is that more adult daughters work than was case in previous years. One study, however, has shown that working and nonworking adult daughters provide about the same number of hours of assistance to their mothers. The employed and nonworking daughters, therefore, provided equal amounts of help with shopping, transportation, household tasks, managing money, service arrangement, and emotional support $[11,17,18]$.

Following the introduction, this study, therefore, examined the family care, social services, and living arrangements as determinants of psychosocial well-being of elderly from selected households in Ibadan, Nigeria.

\section{Objectives of the Study}

The main objective of this study is to examine the family care, social services, and living arrangements as determinants of psychosocial well-being of elderly from selected households in Ibadan, Nigeria.

Other specific objectives are to

(1) examine how family care determines the psychosocial well-being of elderly,

(2) examine how social services determine the psychosocial well-being of elderly,

(3) examine how living arrangements determine the psychosocial well-being of elderly, and

(4) suggest measures which could facilitate the care of elderly.

\section{Research Hypotheses}

Following the introduction and objectives of the study, the following hypotheses were tested at 0.05 level of significance to achieve the objectives of this study.

$\mathrm{Ho}_{1}$ : There will be no significant relationship between family care and psychosocial well-being of elderly.

$\mathrm{Ho}_{2}$ : There will be no significant relationship between social services and psychosocial well-being of elderly.

$\mathrm{Ho}_{3}$ : There will be no significant relationship between living arrangements and psychosocial well-being of elderly.

\section{Methodology}

4.1. Research Design. This study adopted a descriptive survey design in which questionnaires were employed in collecting data from the respondents on the variables studies. 
TABLE 1: Cross-tabulation and chi-square analysis of family care and psychosocial well-being elderly.

\begin{tabular}{|c|c|c|c|c|c|c|c|c|c|}
\hline \multirow{2}{*}{ Family care } & \multicolumn{4}{|c|}{ Respondents' responses to psychosocial Well-being } & \multirow{2}{*}{ Total } & \multirow{2}{*}{$\chi^{2}$ Cal. } & \multirow{2}{*}{$\chi^{2}$ Critical } & \multirow{2}{*}{ df } & \multirow{2}{*}{$P$} \\
\hline & $\begin{array}{l}\text { Strongly } \\
\text { agree }\end{array}$ & Agree & Disagree & $\begin{array}{l}\text { Strongly } \\
\text { disagree }\end{array}$ & & & & & \\
\hline $\begin{array}{l}\text { Health care service } \\
\text { Emotional support }\end{array}$ & $23(8.2)$ & $28(10.0)$ & $27(9.6)$ & $9(3.2)$ & $87(31.0)$ & & & & \\
\hline Care in an illness & $18(6.4)$ & $86(30.6)$ & $17(6.0)$ & $0(0.0)$ & $121(43.1)$ & & & & \\
\hline Financial support & $9(3.2)$ & $19(6.8)$ & $0(0.0)$ & $0(0.0)$ & $28(10.0)$ & 127.9 & 5.23 & 12 & $<.05$ \\
\hline Meal and special needs & $10(3.6)$ & $25(8.9)$ & $0(0)$ & $0(0)$ & $35(12.5)$ & & & & \\
\hline $\begin{array}{l}\text { Home repairs and } \\
\text { housework }\end{array}$ & $7(2.5)$ & $2(0.7)$ & $0(0)$ & $0(0)$ & $9(3.2)$ & & & & \\
\hline Total & 67 & 160 & 44 & 9 & 280 & & & & \\
\hline
\end{tabular}

$\chi^{2}=127.9, \mathrm{df}=12, P<.05$.

4.2. Participants. A total of two hundred and eighty respondents (elderly) were randomly drawn from five local government areas of Ibadan metropolis: Ibadan North, North-West, Ibadan North-East, Ibadan South-East, and Ibadan SouthWest. The two hundred and eighty respondents (male and female) were categorically subdivided into two major groups: literates and illiterates from selected households. 150 (53.6\%) came from literates who were mostly retired civil servants, and other professionals while 130 (46.4\%) were the illiterates who were traders, artisans, farmers, and so on. Their age range was $65-75$ with a mean of 69.0 years and standard deviation of 21.3.

4.3. Instrumentation. The three instruments used in this study were self-reported questionnaire on family care (SQFC), social services questionnaire (SSQ), and selfreported living arrangements questionnaire (SLAQ). The three instruments were author-constructed. The Self-Reported Questionnaire on Family Care measures the nature and patterns of caring for elderly. It has 20 items that adopted the 4-point rating scale ranging from strong agree to strongly disagree. The internal consistency estimate of SQFC is .75 and revalidation reliability of .80 when administered 90 elderly persons after two weeks of administration.

The second social services questionnaire (SSQ) contained 25 items with responses anchor from strongly agree to strong disagree. It measures various forms of social services such as health care services, transportation services, recreation services, home-delivered meal services, housing provision, and legal assistance. The test-retest reliability of the instrument was .83 at 2-week interval and consistency of .81.

The third instrument, self-reported living arrangements questionnaire, containing 15 items, adopted the 3-point rating scale ranging from strongly agree to disagree. The questionnaire measures the associated living arrangements of elderly in later life. The questionnaire has a test-retest reliability of .76 at 2-week interval and internal consistency of .72. All the three instruments were considered valid, through the favourable comments of experts in psychometrics on the suitability of the items.

4.4. Procedure. The questionnaires were administered on the elderly persons (male and female) from selected households randomly drawn from five local government areas of Ibadan metropolis. The questionnaires were administered by the researcher and his research assistants employed. A total of 400 questionnaires were distributed out of which 280 were returned and well administered. This represents a return of $70.0 \%$ which is considered adequate to analyze the results of the study.

4.5. Data Analysis. The data collected were analyzed using chi-square $\left(\chi^{2}\right)$ analysis to establish the relationships between family care, social services, and living arrangements and psychosocial well-being of elderly persons.

\section{Results}

The results of the study obtained for the null hypotheses were presented in Tables 1-3.

5.1. Hypothesis 1. There will be no significant relationship between family care and psychosocial well-being of elderly.

Table 1 shows the relationship between the family care and psychosocial well-being of elderly. The table reveals that $X^{2}$-calculated value $(127.9)$ is greater than $X^{2}$-critical value (5.23) at 12 degree of freedom. The null hypothesis is therefore rejected. This indicates that there is significant relationship between family care and psychosocial well-being of elderly.

5.2. Hypothesis 2. There will be no significant relationship between social services and psychosocial well being of elderly.

Table 2 represents the cross-tabulation and Chi-square analysis of social services and psychosocial well being of elderly. The table shows that $\chi^{2}$-calculated value (191.9) is greater than $\chi^{2}$-critical value (5.23) at 12 degree of freedom. The null hypothesis is therefore rejected and indicates that there is significant relationship between the social services and psychosocial well-being.

5.3. Hypothesis 3. There is no significant relationship between living arrangements and psychosocial well-being of elderly. 
TABLE 2: Cross-tabulation and chi-square analysis of the social services and psychosocial well-being of elderly.

\begin{tabular}{|c|c|c|c|c|c|c|c|c|c|}
\hline \multirow{2}{*}{ Social services } & \multicolumn{4}{|c|}{ Respondents' responses to psychosocial well being } & \multirow{2}{*}{ Total } & \multirow{2}{*}{$\chi^{2}$ Cal. } & \multirow{2}{*}{$\chi^{2}$ Critical } & \multirow{2}{*}{ df } & \multirow{2}{*}{$P$} \\
\hline & $\begin{array}{l}\text { Strongly } \\
\text { agree }\end{array}$ & Agree & Disagree & $\begin{array}{l}\text { Strongly } \\
\text { disagree }\end{array}$ & & & & & \\
\hline Health Care Services & $36(12.9)$ & $9(3.2)$ & $41(14.6)$ & $0(0)$ & $86(30.7)$ & & & & \\
\hline Transportation Services & $14(5.0)$ & $86(30.6)$ & $13(4.6)$ & $8(2.8)$ & $121(43.1)$ & & & & \\
\hline $\begin{array}{l}\text { Information and referral } \\
\text { services }\end{array}$ & $4(1.4)$ & $25(8.9)$ & $0(0.0)$ & $0(0.0)$ & $29(10.3)$ & 191.9 & 5.23 & 12 & $<.05$ \\
\hline Legal assistance & $4(1.4)$ & $31(11.0)$ & $0(0)$ & $0(0)$ & $35(12.5)$ & & & & \\
\hline Housing needs/repairs & $5(1.8)$ & $4(1.4)$ & $0(0)$ & $0(0)$ & $9(3.2)$ & & & & \\
\hline Total & 63 & 155 & 54 & 8 & 280 & & & & \\
\hline
\end{tabular}

$\chi^{2}=191.9, \mathrm{df}=12, P<.05$

TABLE 3: Cross-tabulation and chi-square analysis of the living arrangements and psychosocial well being of elderly.

\begin{tabular}{lccccccc}
\hline \multirow{2}{*}{ Living arrangements } & \multicolumn{2}{c}{ Respondents' responses to psychosocial Well being } & Total & $\chi^{2}$ Cal. & $\chi^{2}$ Critical & df & $P$ \\
& $\begin{array}{l}\text { Strongly } \\
\text { agree }\end{array}$ & Agree & Disagree & & & \\
\hline Living alone & $8(2.8)$ & $50(18.1)$ & $0(0.0)$ & $58(20.7)$ & & \\
Living with children & $8(2.8)$ & $122(43.4)$ & $9(3.2)$ & $739(49.5)$ & 14.4 & 1.64 & 6 \\
Living with relatives/friends & $4(1.4)$ & $70(24.9)$ & $0(0.0)$ & $9(26.3)$ & \\
Living with grandchildren & $0(0.0)$ & $9(3.2)$ & $0(0.0)$ & 280 & \\
\hline Total & 20 & 251 & 9 & & \\
\hline
\end{tabular}

$\chi^{2}=14.4, \mathrm{df}=6, P<.05$.

Table 3 shows the relationship between living arrangements and psychosocial well-being of elderly. The results obtained from the table show that $\chi^{2}$-calculated value (14.4) is greater than $\chi^{2}$-critical value (1.64) at 6 degree of freedom. The null hypothesis is therefore rejected and indicates that there is significant relationship between living arrangements and psychosocial well-being of elderly.

\section{Discussion of the Findings}

The major goal of this study was to find out the relationship between family care, social services, living arrangements, and psychosocial well-being of elderly.

In Table 1, the influence of family care is significantly related to psychosocial well-being of elderly persons. It was observed that emotional support, care in an illness, financial support, home repairs, and housework have influence on psychosocial well-being of elderly in their later life. This finding is consistent with the findings of Shanas [7], Mancini and Blieszner [8], Okunola [6], and Anderson and Taylor [5] who found that family care was significantly related to psychosocial well-being of elder in that families have been the major resource, and there are always contact relationships between older people and their families or relatives. They also found that a wide array of social, health, and related support services were extended to the aged from their families or relatives.

The results of null hypothesis 2 tested also revealed that social services are significantly positively related to psychosocial well-being of elderly people. This finding corroborates the findings of Heffeman et al. [9], Okunola [6], and Adegoke
[10] in which social services are significantly related to psychosocial well-being of elderly.

One can explain this finding against the background that providing social services from appropriate quarters will lead to the improvement of socioeconomic status of elderly persons. This will eventually make the elderly happy and have positive adjustment on their psychological and social wellbeing in later life. Social service includes income security from their gratuity and pension allowances, and transportation services are also essential for grocery shopping, attending churches services, keeping appointments with doctors and dentists, visiting friends, and maintaining contact with the family. Providing transportation to the elderly will prevent them becoming home bound. Other social services include health care, housing, and employment, and even legal assistance to the elderly is essential in later life.

Finally, the results of null hypothesis 3 had shown that significant positive relationship existed between living arrangements and psychosocial well-being of elderly. The results support the findings of Russell [14], Jylhä and Jokela [15], Hareven [18], Brody et al. [16], Skidmore et al. [12], and Thornson [11] in that they also found that associated with the living arrangements is the increasing freedom older persons now have compared to earlier generations. The number of older people who live alone has increased during recent decades because older people are financially off enough to live by themselves.

An explanation for this finding derives from the fact that living arrangement is found to be that the current generation of older persons are unlike their parents and grandparents in that there is less reliance on kin for assistance because more older people live in their own households, resulting to 
fewer day-to-day contacts with family members they might rely upon for assistance.

\section{Implications of the Findings and Recommendations}

The study had been able to establish that family care, social services, and living arrangements were significantly correlated with psychosocial well-being of elderly.

The findings implicate the need for the framework on the complex system of the elderly services. This framework shows four categories of services to the older people. These categories cover the most common problems of older people. These areas of service are (1) economic, (2) attitude (helping elders and society in general to develop better attitudes toward aging), (3) role making (services that give the aged persons opportunities to play meaningful roles in society), and (4) health care.

The results of this study, therefore, have implications for family service agencies, social workers, nursing homes (for medical assistance), private social service agencies (NGOs), public social service agencies (Governments), and other helping professionals or institutions in meeting the needs of aged.

Following the results of this study, these recommendations were specifically made to improve the needs of the elderly people.

(1) Elderly should be given free medical care in later life. This can be provided by the government through nursing home care which is considered the resource for those elderly who need considerable long-term medical care.

(2) There should be suitable transportation services for the elderly to facilitate access to shops, attend church services, keep appointments with doctors and dentists, visit friends, and maintain contact with the family. This is important for those who can no longer drive or use public transportation.

(3) There should be framework for supportive and protective care that comprises those services provided to frail, ill, or disabled older people to support them and their caretakers maintaining their capacity to live in the community.

(4) There should be preventive care and socialization, services which can be provided through the natural and community systems, and these do not require a large amount of government funding. They can prevent the need for the more expensive supportive and protective care and institutional care for older people.

(5) There should be support to families and people maintaining elderly in their own homes, coupled with suitable and subsidized elder housing. Thus, housing places older people in close proximity to one another seem to encourage a mutual helping network in which, older people look out for and provide companionship for each other.
In conclusion, there is need for social workers to grow because they will support the elder, their families, and the caseworkers for the frail and disabled elderly in the community. They will also provide services to institutionalized aged persons. Nevertheless, the social workers will provide protective services and serve to empower those unable to stand up for their rights and needs.

\section{References}

[1] D. Gibson, "Broken down by age and gender: "the problem of old women" redefined," Gender and Society, vol. 10, no. 4, pp. 433-448, 1996.

[2] B. L. Neugarten, "Age groups in American society and the rise of the young old," Annals of the American Academy of Political and Social Science, vol. 415, pp. 187-198, 1974.

[3] L. C. Johnson, L. C. Schwartz, and D. S. Tate, Social Welfare: A Response to Human Need, Allyn and Bacon, Boston, Mass, USA, 1997.

[4] J. Aronson, "Women's sense of responsibility for the care of old people: 'but who else is going to do it?', Gender and Society, vol. 6, no. 1, pp. 8-29, 1992.

[5] M. L. Anderson and H. F. Taylor, Sociology: Understanding a Diverse Society, Wadsworth Publishing Company, Belmont, Calif, USA, 3rd edition, 2004.

[6] M. I. Okunola, Old Age Care. A Hand book for Nigerian Social Workers, Daybis Ltd., Ibadan, Nigeria, 2002.

[7] E. Shanas, "The family as a social support system in old age," The Gerontologist, vol. 19, no. 2, pp. 169-174, 1979.

[8] J. A. Mancini and R. Blieszner, "Aging parents and adult children: research themes in intergenerational relations," in Contemporary Families: Looking Forward, Looking Back, A. Booth, Ed., pp. 249-264, National Council on Family Relations, Minneapolis, Minn, USA, 1991.

[9] J. Heffeman, G. Shuttlesworth, and R. Ambrosino, Social Work and Social Welfare: An Introduction, West Publishing Company, Saint Paul, Minn, USA, 2nd edition, 1992.

[10] T. G. Adegoke, "Socio-economic factors as determinants of caring for the elderly retired civil servants in Ibadan Metropolis, Nigeria," UniQua Research Chronicle, vol. 4, no. 1, pp. 124135, 2003.

[11] J. A. Thornson, Aging in a Changing Society, Brunner/Mazel, Washington, DC, USA, 2nd edition, 2000.

[12] R. A. Skidmore, M. G. Thackray, and O. W. Farley, Services for the Aged. Introduction to Social Work, Allyn and Bacon, Boston, Mass, USA, 1997.

[13] J. Quadagno, “Aging," in Social Problems, G. Ritzer, Ed., Random House, New York, NY, USA, 2nd edition, 1986.

[14] C. H. Russell, Good News about Aging, John Wiley \& Sons, New York, NY, USA, 1989.

[15] M. Jylhä and J. Jokela, "Individual experiences as cultural-a cross-cultural study on loneliness among the elderly," Ageing and Society, vol. 10, no. 3, pp. 295-315, 1990.

[16] E. M. Brody, S. J. Litvin, S. M. Albert, and C. J. Hoffman, "Marital status of daughters and patterns of parent care," Journals of Gerontology, vol. 49, no. 2, pp. S95-S103, 1994.

[17] E. M. Brody and C. B. Schoonover, "Patterns of parent-care when adult daughters work and when they do not," The Gerontologist, vol. 26, no. 4, pp. 372-381, 1986.

[18] T. K. Hareven, "Family and generation relations in the later years: a historical perspective," Generations, vol. 16, no. 3, pp. 7-12, 1992. 


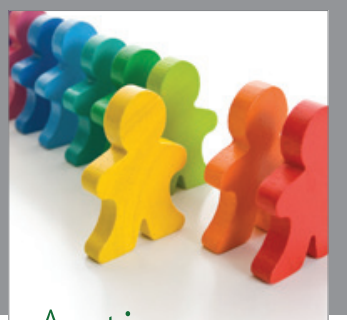

Autism

Research and Treatment
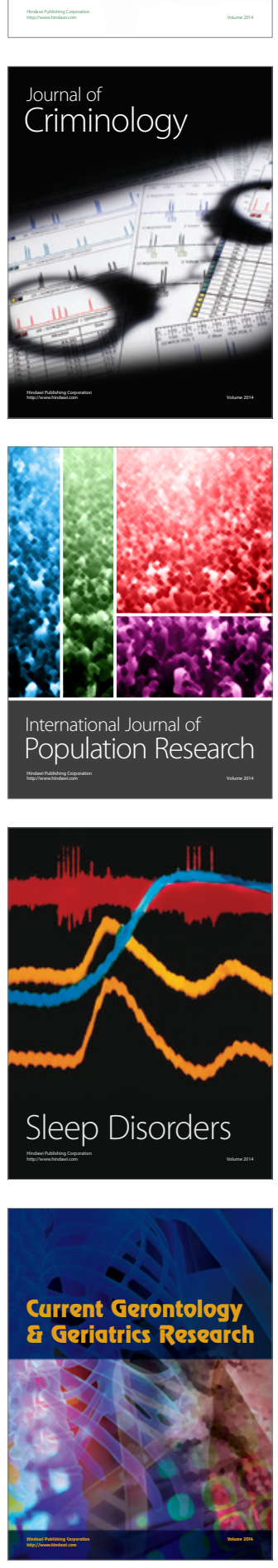
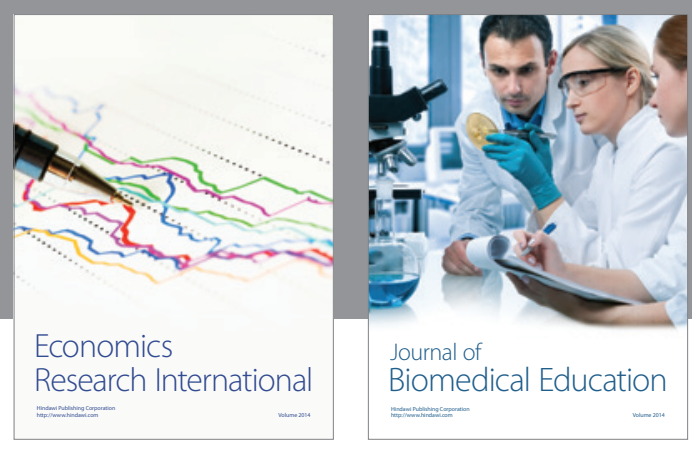

Journal of

Biomedical Education

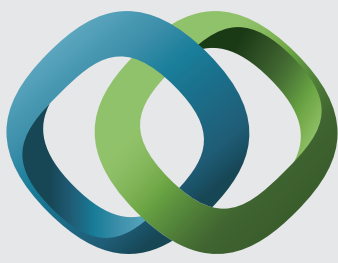

\section{Hindawi}

Submit your manuscripts at

http://www.hindawi.com
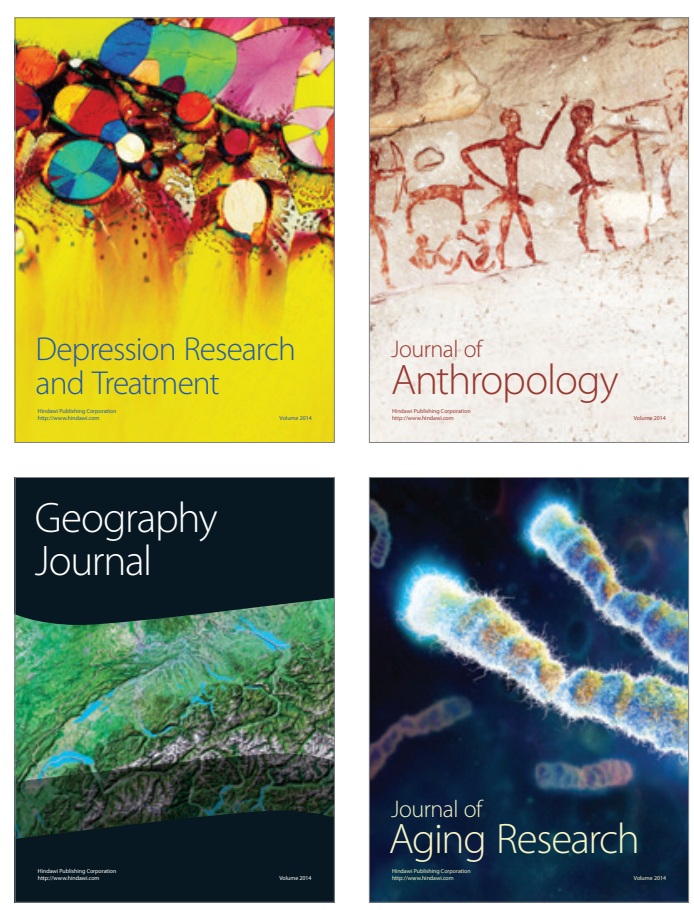

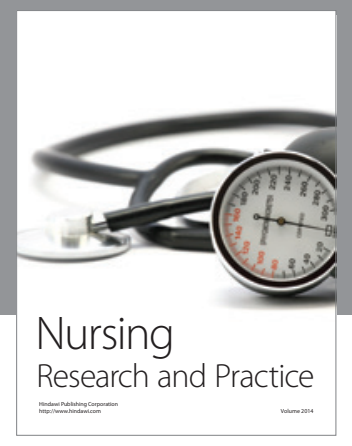

Nursing

Research and Practice

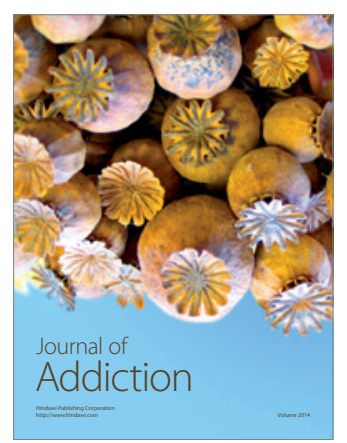

Child Development

Research

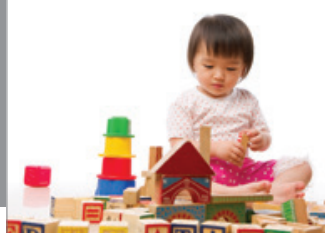

迥
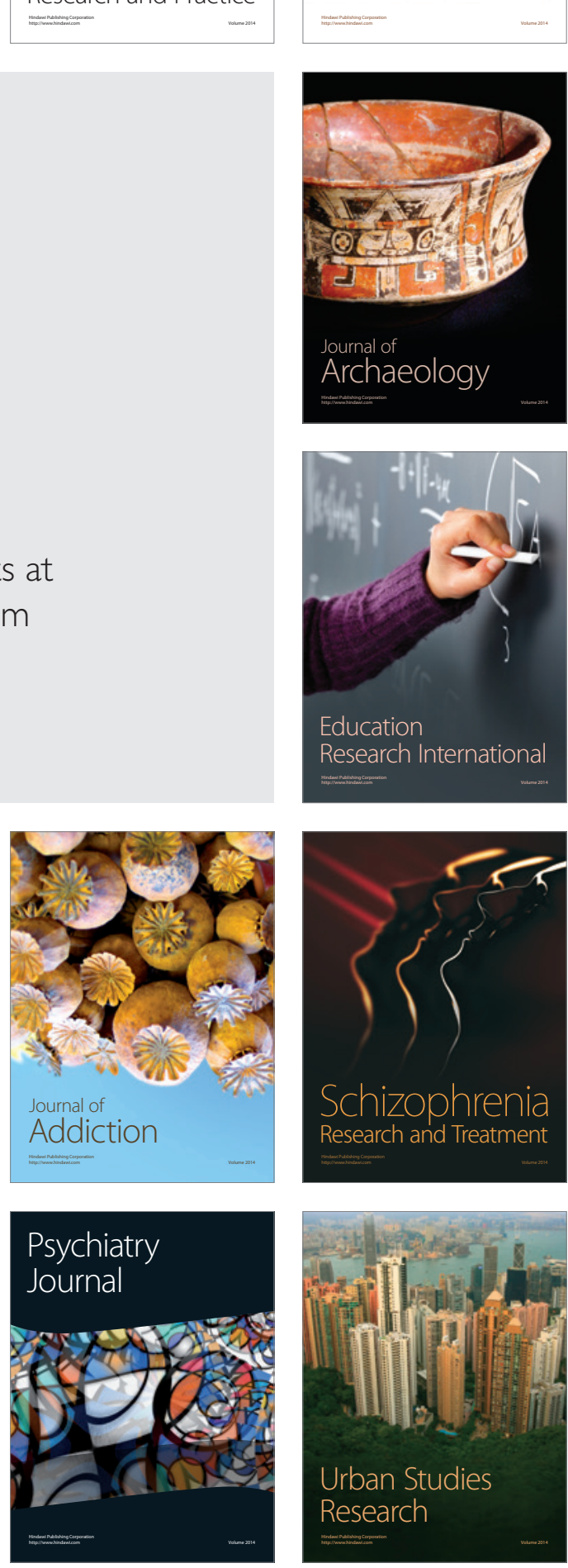